\title{
Fatores Motivacionais no desempenho laboral em funcionários de uma escola Militar em Juazeiro - BA
}

Leila Cristina Oliveira dos Santos ${ }^{1}$; Ana Maria Almeida de Oliveira ${ }^{2}$; Fernanda Roda de Souza Araújo Cassundé3

Resumo: Toda organização busca uma prestação de serviços pautada na eficiência, na eficácia e na qualidade, objetivando sempre resultados cada vez melhores e tentando se manter viva em um mercado de trabalho exigente, globalizado e mutável. Com base nessa busca, percebeu-se que um dos pontos para se alcançar os objetivos desejados em uma organização estava alicerçado na atenção dada a equipe de trabalho, na necessidade de cuidar primeiramente do público interno que gera o perfil da organização. Diante dessa percepção, verificouse a necessidade de se investigar quais os principais fatores que influenciam o desempenho profissional dos funcionários do Colégio da Polícia Militar Alfredo Vianna em Juazeiro-BA, quais são os fatores intrínsecos ou extrínsecos que norteiam esses colaboradores, que fatores servem de propulsores para que atinjam a eficiência e eficácia em seu ambiente de trabalho levando a organização ao rumo desejado e um patamar diferenciado no mercado.

Palavras-Chaves: Fatores motivacionais, Desempenho, resultado

\section{Motivational factors in work performance in Military school officials in Juazeiro-BA.}

\begin{abstract}
Every organization wants a service based in the efficiency, effectiveness and quality, always aiming to better results and trying to stay alive in a demanding, changing and globalized labor market. Based on this search, it was noticed that one of the points to achieve the desired goals in an organization was founded in the attention given to teamwork, the need to first take care of the domestic audience that generates the profile of the organization. Given this perception, there was a need to investigate the main factors that influence the performance of the professional staff of the College of Military Police Alfredo Vianna in Juazeiro-BA, which are the intrinsic or extrinsic factors that guide these employees, factors that serve propellants to achieve efficiency and effectiveness in the workplace leading the organization to the desired direction and a different level in the market.
\end{abstract}

Keywords: Motivational factors, performance, result

\section{Introdução}

Por trás de toda organização estão pessoas que buscam auto-realização pessoal e profissional, essa auto-realização associada ao nível de motivação pessoal de cada um, exerce uma grande influência no rumo de uma organização, na sua forma de prestação de serviços, na eficiência e eficácia de trabalho se tornando uma questão estratégica.

\footnotetext{
${ }^{1}$ Graduada em Matemática pela Universidade de Pernambuco - UPE; Pós-Graduanda em Gestão Pública pela Universidade do Vale do São Francisco- UNIVASF. leilajua@yahoo.com.br (74) 8804.5934.

${ }^{2}$ Graduada em Administração pela Universidade Norte do Paraná - UNOPAR; Pós-Graduanda em Gestão Pública pela Universidade do Vale do São Francisco- UNIVASF. annittaoliver@hotmail.com (74)9110.6045.

${ }^{3}$ Docente do Colegiado de Administração - CADM Universidade Federal do Vale do São Francisco - UNIVASF Lattes: http://lattes.cnpq.br/2696430100313826 Telefone: (87) 2101.6853.
} 
Hoje fala-se muito na busca pela excelência dos resultados, porém para se chegar nessa excelência, uma organização precisa de uma equipe de trabalho motivada, valorizada, satisfeita e direcionada na busca desse objetivo, a ideia passou a ser a substituição das estratégias voltadas para a recompensa (SCHIEHLL E MORISSETTE, 2000), dando lugar as estratégias que proporcionem o bem estar e a satisfação no ambiente de trabalho (EREZ, KLEINBECK, THIERRY, 2001).

Com o advento das novas organizações de trabalho, após a Revolução Industrial, manifestouse o interesse em torno dos aspectos que levariam ao aumento da produtividade humana. Buscou-se compreender quais os fatores capazes de levar os trabalhadores a caminhar em direção aos objetivos da organização, tornando-os colaboradores eficientes e eficazes.

Nesse intuito muitos pesquisadores realizaram estudos a respeito da motivação humana, tentando estabelecer quais seus principais propulsores. Dentre esses pesquisadores podemos citar Abraham Harold Maslow, que criou a teoria da hierarquia das necessidades. Maslow buscou compreender o homem dentro de uma percepção multidimensional, considerando a existência de diversas necessidades, desde as mais básicas até as mais complexas dentro de uma inter-relação dinâmica.

Herzberg (apud AQUINO, 1980) percebeu que as pessoas apresentam diversos tipos e estilos motivacionais), que além dos fatores intrínsecos relacionados à personalidade e a natureza humana, existem também os fatores extrínsecos que podem influenciar na produtividade das pessoas em uma organização. Dentre esses fatores extrínsecos surge o papel do gestor, sua forma de liderar e conduzir sua equipe de trabalho, atuando de forma incentivadora, motivadora ou não, podemos citar também o ambiente de trabalho, os meios disponíveis, as instalações, as ferramentas, a remuneração e as relações interpessoais. Motivação envolve sentimentos de realização e de reconhecimento profissional, manifestado por meio de exercícios das tarefas e atividades que oferecem suficiente desafio e significado para o trabalho (LOPES, 1980, p.23).

O Colégio da Polícia Militar Alfredo Vianna em Juazeiro-BA é uma dessas organizações públicas, que tem por finalidade a busca por uma prestação de um serviço de educação de qualidade, baseado nos pilares da disciplina militar, preparando jovens para a futura inserção em um mercado de trabalho cada vez mais competitivo e dinâmico, incentivando seus alunos a desenvolverem um senso crítico e reflexivo para atuarem como cidadãos. É uma das metas da Instituição que os discentes alcancem uma realização pessoal, buscando o desenvolvimento da integração social, das potencialidades de cada um e um senso de auto-realização. Porém, para essa finalidade ser bem desenvolvida o Colégio da Polícia militar Alfredo Vianna depende de funcionários motivados e bem direcionados, Locke (apud ROBBINS, 1999), explica que metas difíceis, quando aceitas, acarretam um melhor desempenho do que metas fáceis, quando impostas. 
Assim, o objetivo deste trabalho é verificar quais são os principais fatores que dentro do processo comportamental influenciam o desempenho dos funcionários do colégio da polícia Militar Alfredo Vianna em Juazeiro-BA, na busca pelo cumprimento da missão proposta pela organização, quais são as variáveis motivacionais dos colaboradores dessa instituição para atingirem um resultado eficiente e eficaz.

\title{
A Motivação Humana e a Teoria das Necessidades de Maslow
}

A evolução do mercado, com seu dinamismo crescente, fez as organizações perceberem a importância da gestão de pessoas para os rumos da organização, fez as organizações entenderem que seu sucesso depende do seu público interno, e que esse público interno deve estar satisfeito e motivado em seu ambiente de trabalho para juntos alcançarem seus objetivos. Podemos notar esse entendimento no conceito de Gil (2001. p.17):

\begin{abstract}
Gestão de Pessoas é a função gerencial que visa a cooperação das pessoas que atuam nas organizações para o alcance dos objetivos tanto organizacionais quanto individuais. Constitui, a rigor, uma evolução das áreas designadas no passado como Administração de Pessoal, Relações Industriais e Administração de Recursos Humanos. Essa expressão aparece no final do século XX e guarda similaridade com outras que também vem popularizando-se, tais como Gestão de Talentos, Gestão de Parceiros e Gestão do Capital Humano.
\end{abstract}

Motivação origina-se do latim mover-se, sendo a área da ciência psicológica que estuda os fatores que dão energia ou estimulam determinado comportamento, ou seja, como tal comportamento inicia-se, direciona-se e sustenta-se (GAZZANIGA E HEATHERTON, 2005), pode ser definida também como sendo "o processo responsável pela intensidade, direção e persistência de esforços de uma pessoa para o alcance de uma determinada meta" (ROBBINS, p.132, 2005) .

Quando se fala de motivação e auto-realização de pessoas em um ambiente de trabalho, tratase de um universo complexo e cheio de particularidades e por isso estimular a motivação no meio profissional passou a ser um desafio para as organizações, para os gestores e uma estratégia de mercado, na busca por melhores resultados.

Antes da revolução industrial, a principal ferramenta utilizada como estímulo motivador era a punição, em suas diversas formas, psicológica, restritiva e até mesmo física, porém com o tempo as organizações perceberem que dessa forma não se conseguia os melhores resultados.

Não existia nas organizações da época nenhum tipo de estrutura adequada para as pessoas, eram ponderados os valores e tradições da época, as decisões oriundas do topo, junto com o estabelecimento de regras e regulamentos determinados e inquestionáveis (WITKOWSKI, DUARTE e GALLINA, 2007). 
Com a revolução industrial e a necessidade de produção em larga escala, pensava-se em produzir mais e em menos tempo, instalou-se uma ideia equivocada de que a motivação vinha do dinheiro.

Porém percebeu-se que somente o dinheiro não era suficiente e que os indivíduos necessitavam de mais, necessitavam suprir suas necessidades pessoais, desenvolver seu senso de autorealização, proteção, respeito.

A partir de então as organizações perceberam que necessitavam entender o universo motivacional, percebeu-se que os interesses organizacionais dependiam desse estudo e a partir de então vários estudiosos passaram a se dedicar ao assunto.

As constantes transformações das teorias administrativas organizacionais, impulsionadas pelo avanço das inovações tecnológicas mundiais, trouxeram às empresas mudanças radicais no trato com os indivíduos, como consequência das interferências ocasionadas pelos fatores externos às organizações, exercendo total domínio sobre a ideia e administração da gestão de pessoas, tornando notória a evolução do conceito de capital humano e gestão de pessoas, e como as influências de tais teorias ainda predominam nas organizações atuais (PEREIRA, COUTINHO e JOHAN, 2003).

Nessa área destacou-se o conhecimento e os estudos de psicólogo norte americano Abraham Maslow, o famoso guru gerencial, foi quem liderou conceitos como gerenciamento esclarecido, sinergia, criatividade, hierarquia de necessidades inatas e auto- realização.

Maslow desenvolveu técnicas de analisar e observar o comportamento humano no ambiente de trabalho, ele afirmava que quanto mais satisfeito e tranqüilo emocionalmente o individuo estivesse mais produtivo e criativo essa pessoa seria em seu ambiente de trabalho. Sua pesquisa se baseava na personalidade humana e no leque de necessidades e motivos inerentes ao ser humano, que envolvem segurança, proteção, estima, relacionamento com o grupo, amor e principalmente auto-realização.

O estudo da teoria da motivação humana introduzida por Maslow ao final da década de 1940 teve como principal atributo o comportamento social e a integração entre os funcionários das companhias da época, enfatizando a prioridade para as necessidades psicológicas e sociais, interagindo com ambiente organizacional, conciliando harmonia organizacional e levando o indivíduo a perceber sua importância dentro da organização (WITKOWSKI, DUARTE e GALLINA, 2007).

O pesquisador Abraham Harold Maslow via o ser humano como um ser de várias dimensões, várias facetas, com várias necessidades, cada necessidade ocupando um grau de importância, de valor, se estabelecendo de forma hierárquica na vida das pessoas. Ele entendeu que a motivação era o estímulo necessário para a satisfação da necessidade dominante e na medida em que uma necessidade era suprida, logo em seguida surgia outra. 
O homem é um animal que deseja e que raramente alcança um estado de completa satisfação, exceto durante um curto tempo. À medida que satisfaz um desejo, sobrevém outro que quer ocupar seu lugar. Quando este é satisfeito, surge outro ao fundo. É característica do ser humano, em toda a sua vida, desejar sempre algo (MASLOW apud CHIAVENATO, 1999).

Pensando dessa forma o grande estudioso criou uma teoria que se chamou teoria da hierarquia das Necessidades, essa teoria estabelecia que as necessidades do ser humano eram divididas em cinco etapas, distribuídas em ordem hierárquica de prioridades a serem atendidas. Essas etapas são: necessidades fisiológicas, necessidades de segurança, necessidades sociais, necessidades de estima e necessidades de auto-realização. Segundo Maslow (2000, p.105) "as necessidades vão se tornando mais sofisticadas à medida que mudamos de nível".

\section{Maslow e a Hierarquia das Necessidades}

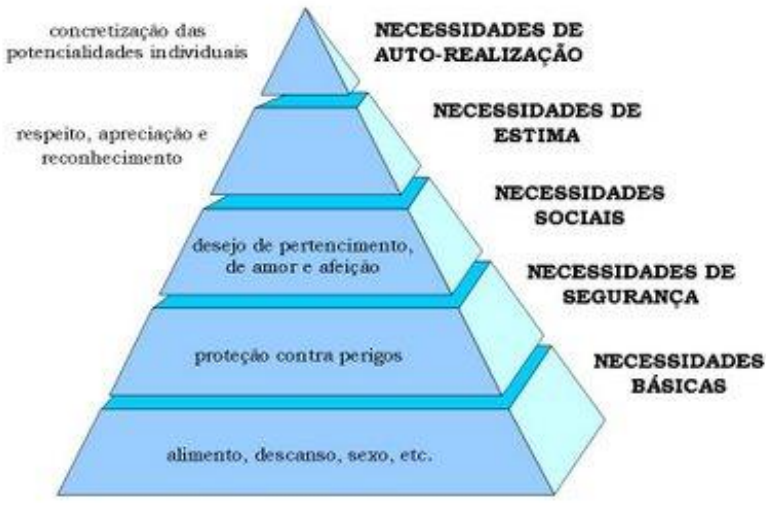

Figura 1: Pirâmide das necessidades humanas Fonte: Adaptada de Maslow (2003)

Estas necessidades estão dispostas em uma pirâmide, que na base traz as necessidades básicas do ser humano, se elevando em níveis até as necessidades mais densas.

[...] as necessidades humanas estão arranjadas em uma pirâmide de importância no comportamento humano, na base da pirâmide estão as necessidades mais baixas e recorrentes - as chamadas necessidades primárias -, enquanto no topo estão as mais sofisticadas e intelectualizadas - as necessidades secundárias. (CHIAVENATO, 2004, p. 66).

As necessidades fisiológicas estão associadas as necessidades básicas de sobrevivência biológica, que incluem situações como necessidade de sexo, alimentação, necessidade de dormir e outras necessidades corporais.

As necessidades de segurança estão intimamente ligadas a necessidade de proteção contra as ameaças ou perigos físicos e emocionais. 
Já as necessidades sociais envolvem as carências de amor, integração, afeição e aceitação social.

As necessidades de estima incluem os fatores de internos e externos de estima, auto-respeito, reconhecimento, senso de competência, prestígio. Gil (2001, p. 206) ressalta que a teoria de Maslow é muito importante para o ambiente de trabalho, porque evidencia que as pessoas não necessitam apenas de recompensas financeiras, mas também de respeito e atenção dos outros.

Ao final as necessidades de auto-realização, que são consideradas as mais elevadas do ser humano, são as necessidades que impulsionam o individuo a ser aquilo que é capaz de ser, têm a função de potencializar as aptidões e capacidades de cada ser.

Para Maslow, a implicação prática da teoria é, obviamente, que alguma coisa poderá atuar como fator motivador para alguém. Podemos dizer que o motivador é um sentido, é algo que impulsiona a pessoa a querer ir em direção a ação.

As necessidades atuam sempre em conjunto, prevalecendo a mais elevada, desde que as inferiores estejam satisfeitas. Assim, uma reação comportamental é um canal, através do qual, várias necessidades fundamentais podem ser expressas ou satisfeitas conjuntamente. Kondo (1994, p.17) afirma que "as necessidades humanas não ascendem à hierarquia em sequência ordenada, ou seja, todas as cinco necessidades estão sempre presentes, mas sua importância relativa gradativamente varia de um nível baixo para um alto, conforme nosso padrão de vida se eleva [...]. Ao pensar a respeito da motivação humana, é importante reconhecer que os seres humanos estão sempre sentindo necessidades de vários tipos".

Maslow, ampliou sua teoria sugerindo que a organização assumisse a construção de uma ponte entre as necessidades básicas e de auto-realização dos indivíduos.

A teoria de Maslow, influenciou significativamente as organizações que começaram a sofrer transformações importantes e passaram a ter uma visão humanizada da gestão, buscando a valorização do profissional em seu ambiente de trabalho e buscando meios que despertassem a motivação de cada pessoa.

Os estudos de Maslow determinaram para o campo teórico da Administração, uma maneira de entender e controlar a dinâmica que se estabelece entre trabalhador e organização. Ao oferecer o atendimento das necessidades básicas do homem, a organização impulsiona-o a produção, motivandoo a buscar novas realizações, e uma vez satisfeita à necessidade, esta não o motiva mais (ROBBINS, 1999).

Maslow, após estruturar conceitualmente o estudo da motivação humana, estabeleceu uma distinção nítida entre motivação de deficiência e motivação de crescimento.

Para o estudioso, a motivação de deficiência está associada a necessidades que o individuo sente que precisa suprir através de outras pessoas ou do meio externo. 
A motivação de crescimento, por sua vez, ocorre quando o passo seguinte é subjetivamente mais agradável, mais feliz, intrinsecamente mais satisfatório do que o nível anterior, com o qual nos familiarizamos. Bergamini (1982, p.24) afirma que: “é, no entanto, na busca dos objetivos motivacionais que as pessoas experimentaram maiores níveis de satisfação. São necessidades de crescimento e revelam uma tendência de todo ser humano em realizar plenamente o seu potencial.

Quando Maslow conceitua a existência de uma motivação por crescimento, mais ligada a fatores internos, inerentes a pessoa e outra chamada motivação por deficiência, mais ligada a fatores externos inerentes a estímulos de terceiros e ao meio ambiente, ele nos possibilita pensar nas motivações intrínsecas e extrínsecas para cada indivíduo.

\section{Motivação Intrínseca e Motivação Extrínseca}

Motivação é o resultado da interação entre o indivíduo e a situação que o envolve (MASLOW, 1996).

Os indivíduos sofrem diferentes influências motivacionais em diferentes níveis que variam ao longo do tempo. Essas influências motivacionais podem ser de dois tipos: motivações intrínsecas e motivações extrínsecas. A presença desses fatores deixa as pessoas satisfeitas o bastante para que outros fatores possam motivá-las (GIL, 2001, p. 208).

Quando se fala da motivação intrínseca, se fala da motivação que cada pessoa produz no seu interior, que está relacionada aos motivos pessoais de cada indivíduo. Os fatores pessoais são todos aqueles em que alguém é impulsionado a um objetivo sem saber exatamente por quê. Neste caso a pessoa avalia algo como motivante simplesmente por que é importante para ela, é um valor pessoal que não há palavras que discriminem precisamente tal energia.

Para Goleman (2001) é necessário ressaltar que, na medida em que nossas emoções atrapalham ou aumentam nossa capacidade de pensar e fazer planos, de seguir treinando para alcançar uma meta distante, solucionar problemas e coisas assim, definem os limites de nosso poder de usar nossas capacidades mentais inatas, e assim determinam como nos saímos na vida. E na medida que somos motivados por sentimentos de entusiasmo e prazer no que fazemos - ou mesmo por um grau ideal de ansiedade, esses sentimentos nos levam a conquista.

Os fatores intrínsecos interagem com o conteúdo do cargo ocupado e com a natureza das tarefas exercidas, por isso envolvem sentimentos de crescimento individual, reconhecimento profissional e auto-realização, estão sob o controle do indivíduo. Esses fatores quando atuam positivamente provocam a satisfação nas pessoas, porém quando agem negativamente eles a evitam. 
A motivação extrínseca está relacionada aos fatores provocativos, a outras situações do meio externo que podem estimular os indivíduos. Os fatores ambientais são todos aqueles que auxiliam alguém a ser impulsionado a uma meta através de algo claro, objetivo, como por exemplo, elogio, recompensa, vivenciar experiências em um ambiente agradável para a pessoa, etc. Neste caso, o fator ambiental auxilia a sustentar a motivação inicial em realizar uma tarefa. Os impulsos externos do ambiente são condicionantes do comportamento de cada indivíduo o que também afeta o nível motivacional (BERGAMINI E CODA, 1995).

Nesse caso os fatores se situam no ambiente que rodeia os indivíduos e envolvem as condições dentro das quais eles desenvolvem seu trabalho, nesse caso os fatores estão fora do controle das pessoas.

Juntas elas direcionam as pessoas na satisfação de suas necessidades e na busca de seus objetivos, quando o gestor e a organização conseguem entender e trabalhar esses fatores motivacionais todos ganham.

\section{O Papel do gestor na motivação}

Com as mudanças sofridas no ambiente organizacional, as variações permanentes do mercado, com o surgimento da era da industrialização neoclássica, em que a competitividade entre as organizações cresceu consideravelmente, os acordos comerciais passaram a ter importância mundial. A inovação tomou o lugar das tradições passadas, trazendo nova visão da gestão administrativa, originando a ideia da teoria da administração de recursos humanos, em conjunto com o desenvolvimento vertiginoso tecnológico, propiciando às pessoas o reconhecimento de sua influência, considerando o fator humano como recursos vivos para as organizações:

A Administração de Recursos Humanos cedeu lugar a uma nova abordagem: A Gestão de Pessoas. As pessoas deixaram de ser simples recursos (humanos) organizacionais para serem abordadas como seres dotados de inteligência, conhecimentos, habilidades, personalidades, aspirações, percepções [...]. (CHIAVENATO, 2009, p. 11)

Os gestores perceberam que para avaliar, entender e administrar os recursos humanos das organizações era necessário o aprofundamento nas teorias e práticas de comportamento organizacional tais como motivação e liderança.

O gestor que visa obter uma liderança de sucesso, precisa conhecer de perto as necessidades, $\mathrm{o}$ grau de interesse e anseios de cada colaborador, apesar de a motivação ser individual é utilizada apenas uma receita para motivar todo grupo, partindo deste pressuposto compreende-se a importância 
do gestor para obtenção de êxito neste processo, DAMETTO ( 2008 ), é ainda mais contundente quando afirma que "A boa liderança requer também boa equipe".

Conseguir a união entre a satisfação individual e os objetivos da organização tem sido o grande alvo dos gestores dentro das empresas, a preocupação das empresas com a motivação dos seus colaboradores é grande, na tentativa de proporcionar o bem estar de seus funcionários, e principalmente porque o elemento motivação é um dos grandes elementos influenciadores da produtividade.

Segundo DRUCKER (1954, P. 341) registra que "o trabalho do gerente é similar ao trabalho do maestro, sendo que o gerente, além de conduzir a orquestra, desempenha também o papel de interprete". O gestor é o responsável em criar um ambiente propicio para que sejam realizados os objetivos da empresa, cabe a ele enxergar e projetar ações juntamente com seus colaboradores. Um líder motivador sabe que o respeito não se garante pela imposição mais sim pelo reconhecimento do seu grupo, que seguem suas sugestões não por submissão, mais sim por acreditarem nos seus propósitos e por confiarem na sua visão. O bom líder deve ser parte da equipe, parceiro, deve dividir as tarefas e ser cúmplice do seu time, desta forma o grupo de maneira natural vai tornando-se homogêneo.

O gestor dentro de uma organização passou a ser mais que um líder, passou a ser um mediador da atuação, participação e envolvimento dos colaboradores, buscando ser referencia através da cumplicidade na delegação de tarefas. Um líder tem o papel de direcionar as ações, confiante no potencial dos seus colaboradores, para exercer com qualidade este papel é de fundamental importância que o gestor agregue a sua função virtudes como: determinação, proatividade, o hábito de saber ouvir e de estar aberto para sugestões, bom humor, espírito de equipe, profissionalismo e comunicação direta e clara, BERNARDES (2003, p. 183) enfoca a comunicação como fator altamente importante para os envolvidos em função de responsabilidade.

Dentro da atual visão organizacional um gestor deve atuar sendo um gerenciador que não se garante pela imposição mais sim pelo reconhecimento do seu grupo, que seguem suas sugestões não por submissão, mais sim por acreditarem nos seus propósitos e por confiarem na sua visão, que dessa forma estará alinhada aos fatores motivacionais de cada um.

Então entendendo o quanto é importante a presença da motivação nos ambientes organizacionais, surgiu a necessidade de se realizar esta pesquisa que mostrará, quais são os principais fatores organizacionais que influenciam os funcionário do Colégio da Polícia Militar Alfredo Vianna em Juazeiro-Bahia. 
A pesquisa teve caráter bibliográfico e de campo, tendo sido realizada no Colégio da Polícia Militar Alfredo Vianna em Juazeiro-Bahia, no período de julho a agosto de 2014.

O Colégio da Polícia Militar passou a funcionar no ano de 2006, atendendo a alunos do ensino fundamental e médio.

Utilizou-se a pesquisa de base quantitativa, onde o pesquisador tem o contato direto com o grupo a ser estudado, sem interferir em suas respostas.

O colégio é composto por 35(trinta e cinco) policiais militares, que desempenham funções de gestão, licitação, guarda de patrimônio e educação militar.

Participaram da pesquisa 20 (vinte) policiais militares que trabalham na instituição, desempenhando funções diversas. Esse quantitativo se baseou em uma amostra intencional, priorizando os sujeitos que exerciam funções diretamente ligadas à execução do serviço educacional militar.

Para aquisição dos dados foi aplicado um questionário com perguntas abertas e fechadas, com observação direta no campo. Foram elaboradas quatorze questões simples, direcionadas ao tema: fatores motivacionais.

As perguntas foram realizadas com um grau fácil de compreensão e de rápida resolução, para que não houvesse sobrecarga de tempo para o entrevistado.

\section{Análise dos Dados}

A pesquisa teve caráter bibliográfico e de campo através de um questionário, visando observar quais os principais fatores motivacionais influenciam os funcionários do Colégio da Polícia Militar Alfredo Vianna.

Após a aplicação do questionário composto por 14(quatorze) enunciados, com participação de 20 (vinte) prepostos, pôde-se verificar o perfil desses funcionários que se apresentaram como 70\% (setenta por cento) do gênero masculino e 30\% (trinta por cento) do gênero feminino demonstrando suas visões em relação ao serviço desenvolvido e principais fatores motivacionais que os impulsionam nesta instituição.

Dentre os entrevistados $85 \%$ (oitenta e cinco por cento) estão acima dos trinta anos de idade e $15 \%$ (quinze por cento) não responderam ao enunciado. Este quantitativo mostra que a maior parte do público envolvido na pesquisa é composto por indivíduos psicologicamente maduros, levando-se em consideração que os indivíduos entrevistados possuem capacidade de discernimento, de racionalidade 
e de pensamento lógico, e possuem também a capacidade para agir diante de uma situação e possuem senso de sociabilidade.

Tabela 01- Quantitativo pesquisado em razão do gênero e idade

\begin{tabular}{|c|c|c|c|}
\hline Sexo & $\begin{array}{l}\text { Quantitativo } \\
\text { Pesquisado }\end{array}$ & Idade & Quantitativo \\
\hline Masculino & 14 & \multirow[t]{2}{*}{$30-50$} & \begin{tabular}{l}
\multicolumn{3}{c}{13} \\
$(02-$ Não \\
informaram a \\
idade $)$
\end{tabular} \\
\hline Feminino & 06 & & $\begin{array}{lr} & 04 \\
(01 \quad- & \text { Não } \\
\text { informou } & \text { a } \\
\text { idade }) & \end{array}$ \\
\hline
\end{tabular}

Foi verificado que 15\% (quinze por cento) dos entrevistados possuem pós-graduação, 70\% (setenta por cento) possuem nível superior completo e apenas 15\% (quinze por cento) possuem nível superior incompleto, demonstrando se tratar de um público instruído, atualizado e preparado para a execução do serviço.

Do público envolvido na pesquisa $85 \%$ (oitenta e cinco por cento) já trabalham na Polícia Militar do Estado da Bahia a mais de 10 (dez) anos, e apenas 10\% (dez por cento) possuem menos de 10 (dez) anos de serviços prestados para a Polícia militar, ressaltando ainda que 5\% (cinco por cento) do público não informou o tempo de serviço. Porém, o colégio da Polícia Militar Alfredo Vianna tem apenas 8 (oito) anos de criação e atendimento ao público e apenas 55\% (cinquenta e cinco por cento) do seu efetivo está lotado no colégio desde sua criação, $15 \%$ ( quinze por cento) estão lotados entre 2(dois) e 3(três) anos, $10 \%$ (dez por cento) possuem apenas 1(um) ano de serviço prestado nesta Unidade e $20 \%$ (vinte por cento) está lotado a menos de 1(um) ano.

Tabela 02- Relação do tempo de serviço e do tempo de trabalho na atual organização

\begin{tabular}{l|c|c|c}
\hline $\begin{array}{l}\text { Tempo de } \\
\text { serviço } \\
\text { (anos) }\end{array}$ & Quantitativo & $\begin{array}{c}\text { Tempo na } \\
\text { atual } \\
\text { organização }\end{array}$ & Quantitativo \\
\hline $00-10$ & 02 & $\begin{array}{c}\text { Menos de } 1 \\
\text { ano }\end{array}$ & 04 \\
\hline $11-20$ & 10 & $1-5$ anos & 05 \\
\hline $21-35$ & 07 & $6-8$ anos & 11 \\
\hline
\end{tabular}


Quando questionados sobre suas funções e sobre o quanto gostavam da função desempenhada atualmente no local de trabalho, $75 \%$ (setenta e cinco por cento) afirmou gostar muito da função que atualmente ocupa no colégio, $15 \%$ (quinze por cento) informaram que gostam um pouco da atual função desempenhada e 10\% (dez por cento) informaram que não gostam da função atual.

Outro item do questionamento se referia a classificação pelo entrevistado da remuneração recebida pelos serviços prestados na instituição, sendo verificado que apenas $10 \%$ (dez por cento) classificaram a remuneração percebida como excelente, $75 \%$ (setenta e cinco por cento) a classificaram como boa e $15 \%$ (quinze por cento) classificaram com ruim.

No contexto das organizações, o relacionamento interpessoal é de extrema importância. Um relacionamento interpessoal positivo contribui para um bom ambiente dentro da empresa, o que pode resultar em um aumento da produtividade. No trabalho, esse relacionamento saudável entre duas ou mais pessoas é alcançado quando as pessoas conhecem a si mesmas, quando são capazes de se colocar no lugar dos outros (demonstram empatia), quando expressam as suas opiniões de forma clara e direta sem ofender o outro (assertividade), são cordiais e têm um sentido de ética. Nessa ótica quando questionados a respeito da relação com os colegas de trabalho, $25 \%$ (vinte e cinco por cento) do efetivo do colégio classificou suas relações interpessoais como excelente e $75 \%$ (setenta e cinco por cento) classificaram como boa suas relações com seus colegas de trabalho.

Outro questionamento importante se referia a relação do subordinado com seu chefe. Dentro da atual concepção do universo corporativo a relação entre o chefe e seu subordinado vem se alterando, e os profissionais e empresas devem se enquadrar a essa nova realidade, formada pela colaboração entre as partes, comunicação clara e trabalho em equipe. Dentro dessa percepção $15 \%$ (quinze por cento) dos entrevistados classificaram sua relação com o chefe como excelente e $85 \%$ (oitenta e cinco por cento) classificaram como boa.

A Organização Mundial da Saúde (2010) dimensiona a saúde, o bem-estar e a segurança no trabalho como aspectos de fundamental importância na produtividade, competitividade e sustentabilidade das organizações: "A riqueza do negócio depende da saúde dos trabalhadores" e define local de trabalho saudável como aquele em que "trabalhadores e gestores colaboram em um processo contínuo de melhoria para proteger e promover a saúde, o bem-estar, a segurança e sustentabilidade do local de trabalho." Quando os entrevistados foram questionados quanto as instalações físicas e as ferramentas de trabalho, verificou-se que 70\% (setenta por cento) acham que as instalações e as ferramentas de trabalho são boas e 30\% (trinta por cento) classificaram esses itens como ruins. 
Tabela 03- Demonstrativo Comparativo em porcentagem da satisfação quanto aos itens que podem influenciar a atuação no ambiente de trabalho

\begin{tabular}{|c|c|c|c|c|c|c|c|c|c|}
\hline \multicolumn{10}{|c|}{ (\%) Percentual } \\
\hline $\begin{array}{l}\text { Gosta muito } \\
\text { da função } \\
\text { que Ocupa } \\
\text { atualmente }\end{array}$ & $75 \%$ & $\begin{array}{l}\text { Percentual } \\
\text { que } \\
\text { consideram } \\
\text { excelente a } \\
\text { remunera- } \\
\text { ção }\end{array}$ & $10 \%$ & $\begin{array}{l}\text { Consideram } \\
\text { excelente a } \\
\text { relação com } \\
\text { os colegas de } \\
\text { trabalho }\end{array}$ & $25 \%$ & $\begin{array}{c}\text { Consideram } \\
\text { excelente a } \\
\text { relação } \\
\text { com o } \\
\text { chefe }\end{array}$ & $15 \%$ & $\begin{array}{l}\text { Consideram } \\
\text { excelente as } \\
\text { instalaçãoes } \\
\text { físicas e } \\
\text { ferramentas } \\
\text { de trabalho } \\
\end{array}$ & $15 \%$ \\
\hline $\begin{array}{l}\text { Gosta um } \\
\text { pouco da } \\
\text { função que } \\
\text { Ocupa } \\
\text { atualmente }\end{array}$ & $15 \%$ & $\begin{array}{l}\text { Percentual } \\
\text { que } \\
\text { consideram } \\
\text { boa a } \\
\text { remuneração }\end{array}$ & $75 \%$ & $\begin{array}{c}\text { Consideram } \\
\text { boa a relação } \\
\text { com os } \\
\text { colegas de } \\
\text { trabalho }\end{array}$ & $75 \%$ & $\begin{array}{c}\text { Consideram } \\
\text { boa a } \\
\text { relação } \\
\text { com o } \\
\text { chefe }\end{array}$ & $85 \%$ & $\begin{array}{l}\text { Consideram } \\
\text { boas as } \\
\text { instalaçãoes } \\
\text { físicas e } \\
\text { ferramentas } \\
\text { de trabalho }\end{array}$ & $85 \%$ \\
\hline $\begin{array}{l}\text { Total de } \\
\text { satisfação } \\
\text { positiva }\end{array}$ & $85 \%$ & $\begin{array}{l}\text { Total de } \\
\text { satisfação } \\
\text { positiva }\end{array}$ & $85 \%$ & $\begin{array}{c}\text { Total de } \\
\text { satisfação } \\
\text { positiva }\end{array}$ & $100 \%$ & $\begin{array}{c}\text { Total de } \\
\text { satisfação } \\
\text { positiva }\end{array}$ & $100 \%$ & $\begin{array}{c}\text { Total de } \\
\text { satisfação } \\
\text { positiva }\end{array}$ & $100 \%$ \\
\hline
\end{tabular}

Foram feitas duas perguntas aos entrevistados, sendo uma aberta e outra fechada, com o intuito de captar de forma mais clara e direta quais os principais motivos que os entrevistados julgam como influenciadores e motivadores para trabalharem no Colégio da Polícia Militar Alfredo Vianna. E dentre os pontos citados apareceram características como segurança, respeito, remuneração conforto, boa gestão, identificação, equipe de trabalho, amor, credibilidade, desafio e reconhecimento social.

Ressaltando ainda, que dos pontos acima os que mais foram citados na pesquisa foram equipe de trabalho, identificação, segurança e respeito.

Quando a organização efetivamente reconhece seus colaboradores, incentiva as ações e comportamentos que mais deseja ver repetidos. Investir no funcionário é uma estratégia para manter bons colaboradores, passando a ser uma arma poderosa para a organização, pois os colaboradores se sentem valorizados.

O senso de valorização é primordial para o ser humano, pois quando são reconhecidos e apreciados tendem a produzir mais e a trabalhar melhor. Então, quando questionados de que forma seu desempenho é reconhecido pela organização, $10 \%$ (dez por cento) afirmam que de forma excelente e 90\% (noventa por cento) de forma boa, mostrando um bom grau de reconhecimento.

Tabela 04- Demonstrativo em porcentagem da satisfação quanto ao item reconhecimento de desempenho pela organização

\begin{tabular}{l|c}
\hline \multicolumn{2}{c}{$\%$ Percentual } \\
\hline $\begin{array}{l}\text { Consideram seu desempenho } \\
\text { reconhecido de forma } \\
\text { excelente pela organização }\end{array}$ & $10 \%$ \\
\hline $\begin{array}{l}\text { Consideram seu desempenho } \\
\text { reconhecido de forma boa } \\
\text { pela organização }\end{array}$ & $90 \%$ \\
\hline Total de satisfação positiva & $\mathbf{1 0 0 \%}$ \\
\hline
\end{tabular}


O último questionamento se referia ao grau de responsabilidade do colaborador com o seu serviço, levando se em consideração que o ambiente de trabalho, juntamente com os atores envolvidos nesse processo e o grau de reconhecimento dado pela organização ao colaborador, podem interferir no comprometimento e no desenvolvimento de uma consciência do papel de cada indivíduo diante de suas obrigações. Assim sendo 75\% (setenta e cinco por cento) diz ter $100 \%$ (cem por cento) de responsabilidade com o serviço que atualmente desempenha e $25 \%$ (vinte e cinco por cento) se classificaram como tendo $75 \%$ (setenta e cinco por cento) de responsabilidade.

\section{Conclusão}

A presente pesquisa teve a intenção de analisar, quais os fatores internos e externos influenciam o desempenho das pessoas dentro do Colégio da Polícia Militar Alfredo Vianna, observando a relação dos fatores motivacionais com a teoria das necessidades de Maslow e as características sociais e psicológicas dos indivíduos, a influencia do gestor e do ambiente de trabalho na atuação dos profissionais dessa organização no desempenho de suas funções.

Com base no estudo bibliográfico e na pesquisa de campo com aplicação do questionário, foi possível perceber que os profissionais do Colégio da Polícia Militar Alfredo Vianna, se encontram na busca por suprir suas necessidades de segurança, sociais, de estima e auto-realização, que os principais fatores motivacionais que norteiam esses profissionais no cumprimento de seu dever, na prestação de um serviço diferenciado e de excelência estão associados a fatores motivacionais, em sua grande totalidade, de natureza intrínseca, dentre esses fatores foram percebidos itens como desafio, identificação e amor.

Porém, os entrevistados puderam demonstrar que alguns fatores extrínsecos como um ambiente de trabalho saudável, a integração da equipe de trabalho, juntamente com a boa atuação do gestor, proporcionam uma percepção de segurança, respeito, credibilidade e senso de reconhecimento pelo trabalho prestado, o que reflete diretamente no grau de responsabilidade individual perante o exercício de sua funções, no grau de satisfação de cada colaborador e na visão de futuro e crescimento profissional de cada um.

Sem contar que a pesquisa demonstrou que público envolvido não estava prestando um serviço voltado para a busca de remuneração ou qualquer fatores de recompensa como elogios ou promoções, muito pelo contrário demonstrou que o público alvo estava satisfeito com a relação emocional desenvolvida entre o que um indivíduo espera de seu trabalho e o que ele percebe que está obtendo. 
Juntos, tanto os fatores intrínsecos e extrínsecos contribuem para que cada indivíduo supra suas necessidades e contribuam para que cada um assuma sua responsabilidade diante de suas obrigações e cumpram seu dever junto a organização, proporcionando a prestação de um serviço de qualidade.

\section{Referências}

AQUINO, Cleber Pinheiro de. Administração de Recursos humanos introdução- 1. ed. Rio de Janeiro: Atlas, 1980.

BERGUE, Sandro Trescastro. Comportamento organizacional - 2. ed. reimp. - Florianópolis: Departamento de Ciências da Administração / UFSC; [Brasília] : CAPES : UAB, 2012.

BERGAMINI, C.W. Motivação nas organizações. São Paulo: Atlas, 2006.

BERGAMINI, Cecília Whitaker e CODA, Roberto. Psicodinâmica da Vida Organizacional. 2a. ed. - SP: Atlas, 1995.

BERNARDES, J.; FERREIRA, F. P. M. Sociedade e Natureza. In: CUNHA,S.P; CARVALHO, Zenaide. Como manter o empregado motivado? $O$ líder que faz a diferença. $<$ http//www.catho.com.br/cursos/índex.php?p=\&id_artigo=398\&acao=exibir > Acesso em: $10 \mathrm{Jul}$ 2014.CHIAVENATO, Idalberto. Gestão de pessoas: o novo papel dos recursos humanos nas organizações. Rio de Janeiro: Elsevier, 2004.

CHIAVENATO, Idalberto. Gestão de Pessoas. Rio de Janeiro, Campus,1999.

DAMETTO, André. Como se tornar um gestor de gestores. Disponível em. Acesso em: 15 jul. 2008.

DRUCKER, P.F. the practice of Management. New York: Harperc Row, 1954. P.341

EREZ, M.; KLEINBECK, U.; THIERRY, H. Work motivation in the context of a globalizing economy. London: Lawrence Erlbaum, 2001.

GIL, Antônio Carlos. Métodos e técnicas de pesquisa social. 5. ed. São Paulo: Atlas, 1999.

Gestão de Pessoas: enfoque nos papéis profissionais. São Paulo: Atlas, 2001.

Como elaborar projetos de pesquisa. 4. ed. São Paulo: Atlas, 2007.

GAZZANIGA, M.S.; HEATHERTON, T.F. Ciência psicológica. Porto Alegre: Artmed, 2005.

GOLEMAN, Daniel. Inteligência emocional. Rio de Janeiro: Objetiva, 2001.

GUERRA, A . J. T. (Org.) A questão ambiental: diferentes abordagens.Rio de Janeiro: Bertrand Brasil, 2003p.183. 
KONDO, Yoshio. Motivação humana: um fator chave para o gerenciamento. São Paulo: Gente, 1994.

LOPES, Tomás de Vilanova Monteiro. Motivação no trabalho. São Paulo: FGV, 1980.

MASLOW, Abraham Harold. Maslow no Gerenciamento. Rio de Janeiro, Qualitymark, 2000.

OLIVEIRA, José Arimatés de. Gestão de pessoas e comportamento organizacional.<http://www.portal.rn.gov.br/content/aplicacao/searh_escola/arquivos/pdf/gest\%C3\% A3o\%20de\%20pessoas\%20e\%20comportamento\%20organizacional.pdf > Acesso em: 07 Jul 2014.

ORGANIZAÇÃO MUNDIAL DA SAÚDE. Healthy workplaces: a model for action. For employers, workers, policy-makers and practitioners. 2010. Disponível em www.who.int

SCHIEHLL, E.; MORISSETTE, R. Motivation, measurement and rewards from a performance evaluation perspective. Revista de Administração Contemporânea, v. 4, n. 3, p. 7-24, 2000.

PEREIRA, Cláudio de Souza, Maria Teresa Correia Coutinho e Sílvio Luiz Johann. Dimensões funcionais na gestão de pessoas. Rio de Janeiro: Editora FGV, 2003.

ROBBINS, Stephen P. Comportamento Organizacional . Rio de Janeiro: LTC, 1999.

TERCIOTTI, Sandra Helena. O poder, a comunicação e o diálogo no ambiente organizacional. $<\mathrm{http} / / \mathrm{www}$.revistaorganicom.org.br/sistema/index.php/organicom/article/viewFile/1 60/260. pdf > Acesso em: 07 Jul 2014.

WITKOWSKI, Beatriz Maria. DUARTE, Cristiane. GALLINA, Daniela Antonieta. O capital humano e o desenvolvimento econômico Revista Catarinense de Ciência Contábil, Florianópolis, ano ?, v. 6, n. $\quad$ 17, $\quad$ abr $\quad-\quad$ jul $2007 . \quad$ Disponível em:http://www.atena.org.br/revista/ojs2.2.306/index.php/CRCSC/article/view/1051/985. Acesso em $31 / 10 / 2012$.

Como citar este artigo (Formato ABNT):

SANTOS, C.O.; OLIVEIRA, A.M.A.; CASSUNDÉ, F.R.S.A. Fatores Motivacionais no desempenho laboral em funcionários de uma escola Militar em juazeiro - BA. Id on Line Revista de Psicologia, Fevereiro de 2015, vol.9, n.25, p. 123-138. ISSN 1981-1189.

Recebido: $10 / 12 / 2014$

Aceito:12/01/2015 